\title{
Corrigendum: Analysing the future of Broad-Based Black Economic Empowerment through the lens of small and medium enterprises
}

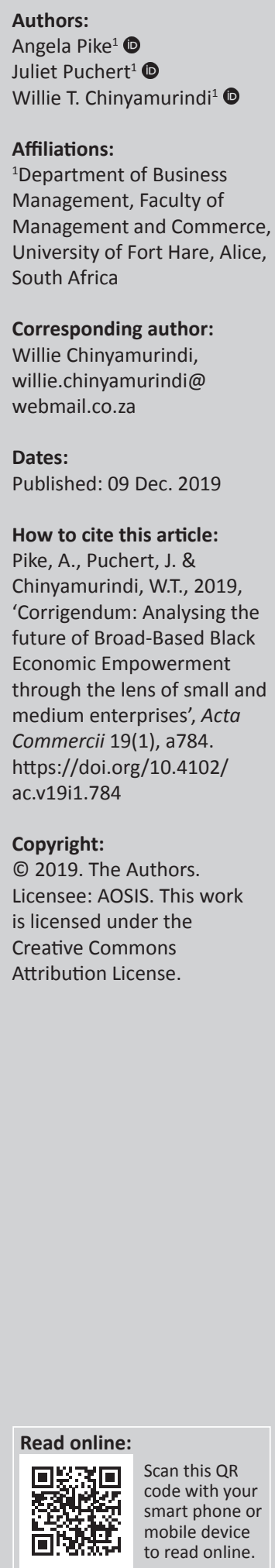

In the version of this article published earlier, the surname of the second author in the in-text reference (Emuze \& Adlam 2013) on page 3 was unintentionally misspelt as 'Adam', which should have appeared as 'Adlam'.

The sentence on page 3, first paragraph, thus has been updated to reflect the correct reference citation:

The current SA government implemented BBBEE as an economic makeover where the policy allows for an increase in the number of black people who manage and own enterprises in the country while decreasing the inequalities that exist in income (Emuze \& Adlam 2013; Tait 2012).

This correction does not alter the study's findings of significance or overall interpretation of the study results. The authors apologise for any inconvenience caused. 